\section{Twenty-four-hour periodicity of the startle response in rats*}

\author{
MICHAEL DAVIS and ARNE SOLLBERGER† \\ Yale University School of Medicine and The Connecticut Mental Health Center \\ New Haven, Conn. 06519
}

Twenty-four rats were presented with 10 tones at a 30 -sec interstimulus interval, once an hour, for $48 \mathrm{~h}$. Startle likelihood showed a pronounced diurnal rhythm with higher responding at night. The period was $24 \mathrm{~h}$ and relatively sinusoidal, with no detectable harmonics. Startle rhythmicity was not simply due to diurnal changes in activity, since activity changes in a control group, which was not exposed to tones, were too small to account for the startle differences. Substantial habituation over the $48 \cdot h$ session was also seen, and the results were discussed in terms of their relevance to the design of habituation experiments.

In recent years, the startle response has been shown to be a suitable response system with which to study habituation (cf. Groves \& Thompson, 1970). It not only shows many parametric features common to other habituation systems (i.e., Thompson \& Spencer, 1966), but also is retained for at least $24 \mathrm{~h}$ (Cohen, 1929) or for even longer intervals when they have been explored (Moyer, 1963), making it appropriate for the study of retention of habituation as well. In order to study retention of habituation within this system, however, great care must be taken to insure that the state of the animal during retention tests is comparable to that during training, since the startle response is extremely sensitive to differences in state. For example, startle likelihood can be influenced by cues that have been paired with shocks (Brown, Kalish, \& Farber, 1951), or prior reward (Armus et al, 1964), or nonreward (Wagner, 1963), as well as background noise (Hoffman \& Fleshler, 1963), sleep deprivation (Stern, 1971), alcohol withdrawal (Gibbins, Kalant, Le Blanc, \& Clark, 1971), or even a single bright light flash (Groves \& Thompson, 1970). Moreover, startle likelihood is also dependent on the time of day in which an eliciting auditory stimulus is delivered, so that, other things being equal, startle amplitude may be greater at night than during the day (Horlington, 1970). This later finding raises problems for the study of startle habituation when long periods of stimulus exposure are used or for the

* This research was supported by USPHS Grants $\mathrm{MH}-13917$ and MH-07114, by NSF Grant GB-23685. and the State of Connecticut. Our thanks to Jean Rosenthal and Lee Schulhof for assistance in running the animals andthe statistical analysis.

tReprint requests should be sent to Nichael Davis, Yale University School of Medicine, 34 Park Street, New Haven, Conn. 06519 . study of retention when retention intervals within a 24 -h period are being analyzed. For instance, in order to study retention of startle habituation within $24 \mathrm{~h}$ of training, it would be necessary to have a knowledge of startle likelihood over an entire 24-h period to use as a baseline to compare retention differences. This kind of data would also provide a fuller description of the nature and complexity of a heretofore relatively unexplored rhythmic phenomenon. Accordingly, the present experiment was designed to evaluate startle likelihood at several points within an entire 24-h period by exposing rats to a brief series of tones, once an hour, for 2 consecutive days.

\section{SUBJECTS}

The Ss were 36 male albino rats of the Sprague-Dawley strain, which ranged in age from 100 to 110 days. Upon receipt from the supplier (Holtzman), the Ss were housed in a large colony room in group cages of 6 Ss each, with food and water continuously available. The colony room was maintained on a 12 -h light/12-h dark schedule, with the period of illumination extending from 0700 to 1900 , Eastem Standard Time. The Ss were housed under these conditions for at least 2 weeks prior to testing.

\section{APPARATUS}

Six stabilimeter devices were housed in one corner of an $8 \times 8 \times 7 \mathrm{ft}$ sound-attenuated chamber (Industrial Acoustics Company). Each stabilimeter consisted of a $3.5 \times 5.5 \times 6.5$ in. Plexiglas and wire mesh cage, supported by four compression springs and by a universal joint at the center of the base. Cage movement resulted in displacement of a loudspeaker coil which rested on the top of the cage. Movement-induced amplified, and a selected amplitude was arranged to produce a relay voltages from the speaker coil were closure, which in turn could operate an electromechanical counter and event recorder. The sensitivity of each circuit was adjusted so that relay closure occurred approximately $50 \%$ of the time when a 0.5 .g weight was dropped onto the stabilimeter from a height of 1 in. A startle response was defined as a relay-activating cage movement during the $50-\mathrm{msec}$ period following onset of each tone.

A 15-in. Altec high-frequency loudspeaker was located 45 in. from each of the six stabilimeters and was employed to provide presentation of a $4,000-\mathrm{Hz} 50-\mathrm{msec} 110-\mathrm{dB}$ tone. The intensity of the tone was measured with a General Radio Model 1551-C sound-level meter with a scale setting of $20 \mathrm{kHz}$, by placing the microphone within each of the six cages and positioning the cages to give comparable decibel reading in each. The designated intensity of the tone does not make allowances for switching transients, which were observable in oscilloscopic recording of the microphone output as an approximately $10 \%$ elevation in the wavefront of the stimulus. A constant white-noise background of $60 \mathrm{~dB}$ was maintained throughout.

\section{PROCEDURE}

Each of six Ss was placed in a stabilimeter at 1100 and, after $1 \mathrm{~h}$, was presented with 10 tones at a $30 \mathrm{sec}$ interstimulus interval (ISI). This series of 10 tones was then repeated every hour for $48 \mathrm{~h}$. The Ss remained in the stabilimeters throughout the 2-day period when food and water were continuously available. Four separate identical replications of the above procedures were conducted, creating a total of 24 Ss.

Two additional replications were conducted to evaluate the degree to which diurnal changes in activity might have contaminated startle measurement. For these $12 \mathrm{Ss}$, all conditions were identical except that the tone generator was disconnected so that they never received a startle-eliciting stimulus. In this way, the electrical gates were closed for a 50-msec period, 10 times an hour, once every $30 \mathrm{sec}$ for $48 \mathrm{~h}$, allowing relay-activating cage movement to be recorded if it occurred. This procedure permitted, therefore, an assessment of the number of times that cage movement in the group that received the auditory stimulus might have been due simply to ongoing activity rather than a true startle and the possible rhythmicity of this influence.

For all replications, the background illumination within the test chamber was the same and consisted of a $12 \cdot h$ light/12-h dark schedule, identical to that on which Ss had previously been maintained in the colony room. Thus, 
at 0700 , the two $100-\mathrm{W}$ bulbs in the ceiling of the IAC room were turned on and remained on until 1900 each day.

\section{RESULTS}

Figure 1 presents the mean percentage startle response over blocks of 10 tones as a moving average over three blocks of 10 tones. The data were combined over all four replications, since the results from each replication were highly similar. Also included in Fig. 1 are the results of the 12 Ss that did not receive tone exposure and indicates the number of times that relay-activating cage movement occurred during the 48 blocks of $10 \quad 50-\mathrm{msec}$ sampling periods. These data have also been shown as a moving average over three 10-sample blocks.

Figure 1 indicates a pronounced diurnal rhythm in startle likelihood, with generally higher levels of startle during the night than during the day. The wide shifts in startle probability over the $48-\mathrm{h}$ session were not attributable to false counts induced by activity changes since the unexposed Ss showed an overall level of only $3 \%$ "startle." While there is some suggestion that these activity counts did show a diurnal rhythmicity, the magnitude of this effect was obviously not sufficient to account for the variations observed in the stimulated group.

Figure 1 also shows a considerable overall decrease in startle probability over the session, indicating substantial habituation under these exposure conditions. Regression analyses found the overall trend of decreasing response probability over blocks to be highly reliable (multiple regression coefficient $=-21.98 \pm 2.01$, $\mathrm{p}<.0001 ;$ baseline $=70.81-21.980$ $\log \mathrm{T}$ ) and best fitted by a logarithmic function which has been shown as a smooth dotted line in Fig. 1. In order to evaluate the rhythmicity of startle likelihood around this baseline, sine curves of varying frequencies were fitted through multiple regression to the individual $S s$ as well as the total mean curve (cf. Sollberger, 1970). The equations were of the type: (startle) $=$ $a+b \log T+c \sin \alpha \mathrm{T}+d \cos \beta \mathrm{T}+$ $e \sin 2 \alpha \mathrm{T}+\mathrm{f} \cos 2 \beta \mathrm{T}+\mathrm{g} \sin 3 \alpha \mathrm{T}+$ $\mathrm{h} \cos 3 \beta \mathrm{T}+\epsilon$. Sine durations of 20 , $21,22, \ldots 28 \mathrm{~h}$ were tried. The best fitting sine durations for different $S$ varied by several hours from the expected 24-h value, but clustered around it. For the total mean curve, the 24-h sine was highly significant [multiple regression coefficients; $c=$ $0.50 \pm 1.04, \mathrm{~d}=-6.33 \pm 1.03$, representing the function (startle) = $70.81-21.980 \log \mathrm{T}+6.353 \sin$ $(-98.0+15(\mathrm{~T}-1)) \pm 11.88$ units, total $\mathrm{SD}=14.55$ units, residual

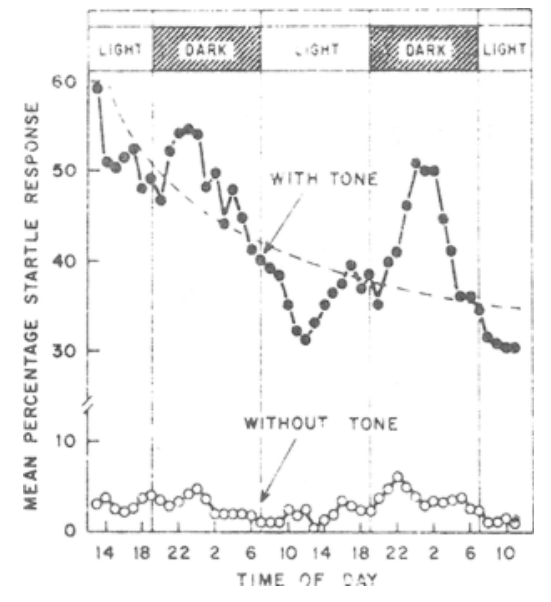

Fig. 1. Mean percentage startle response per block of 10 tones shown as a moving a verage over three 10-tone blocks for the group that was exposed to tones and the mean percentage relay-activating cage movement that occurred at comparable times for the group not exposed to tones.

SD $=11.88$ units, $F=48.8$, $\mathrm{df}=3 / 284, \mathrm{p}<.0001$. $\mathrm{T}=$ time was counted in sequential hour units, with $\mathrm{T}=1$ as the noon starting point.] The peak occurred at $00: 32$, shortly after midnight, and the minimum at 12:32, shortly after noon. The first two harmonics were not statistically significant and indicates that the present startle rhythm was fairly sinusoidal in shape.

\section{DISCUSSION}

The present results confirm the observation of Horlington (1970) that startle likelihood shows a diurnal rhythm with greater responsivity at night than during the day. In fact, the size of the day-night difference under these conditions was quite comparable to that reported by Horlington for Ss at a similar age. The period of the present rhythm was very close to $24 \mathrm{~h}$ and free of harmonics.

It could be argued that under the present experimental conditions, changes in startle likelihood were more a direct result of changes in background illumination during testing than of internal changes in startle propensity, since the lights in the test chamber were always off at night and on in the day. While the study was not designed to evaluate the influence of background illumination during testing, this probably was not the critical variable. Thus, peak responsiveness during dark periods did not occur immediately when the lights went out but rather $4-6 \mathrm{~h}$ later. If dishabituation alone were the cause of heightened responsiveness when illumination conditions were changed, this would be expected to show up at the point of transition rather than hours later. It is more probable that the light-dark schedule synchronized a spontaneous circadian startle response rhythm, as was intended with the present design. Actually, Horlington (1970) found day-night differences even though the illumination in his startle chamber was the same at night and during the day.

The wide variations in startle likelihood over this 2-day session pose serious constraints on the study of retention within a 24-h period following training. For example, if several groups were all given training at the same time of the day, but then tested separately at different retention intervals, a rather complicated nonmonotonic retention curve might be found. Or if a common retention interval were used, say across different studies, but the time of training and testing varied across these studies, substantial retention, or no retention, or even "negative" retention might be reported. In order to study retention of startle habituation, which will be important if habituation is approached as an index of memory, three paradigms might be used. Simplest and most straightforward would be to use only retention intervals that were whole multiples of $24 \mathrm{~h}$, since the period of the startle response rhythm appears to be very close to $24 \mathrm{~h}$. If intervals of less than $24 \mathrm{~h}$ were of interest, however, different groups could be trained at different times but then all tested at the same time of the day. While this would insure comparable test conditions of all retention intervals, it would assume that equivalent amounts of habituation would develop at all times during the diurnal cycle, which probably would not be the case. For this reason, the best design would be one in which all groups would be trained at the same time, half with tone exposure and half without, and then pairs of exposed and unexposed groups would be tested with tones at various intervals thereafter. The performance of the unexposed groups would provide an index of unhabituated response probability at the intervals of interest with which to compare the performance of the habituated groups, generating a retention curve comprising difference scores between pairs of groups at each interval. Actually, several different experiments of this kind, which varied in terms of the exact time of day in which the training session was given, would probably be necessary to evaluate whether the shape of the retention curve would also depend on the part of the diurnal cycle in which training was initiated.

Finally, it should be pointed out that the present exposure conditions 
resulted in substantial habituation. In fact, the absolute amount of habituation in the present experiment was as large or larger than previous experiments which employed a similar apparatus but shorter ISIs with no periods of silence between tone blocks (Davis \& Wagner, 1968, 1969). This is consistent with a recent study that found greater long-term habituation, the longer the ISI (Davis, 1970), and suggests that periods of silence following tone exposure may be as effective or even more effective in producing habituation than continuous exposure, perhaps by not allowing sensitization to develop (Groves \& Thompson, 1970).

\section{REFERENCES}

ARMUS, H. L., CARLSON, K. R. GUINAN, J. F., \& CROWELL, R. A. Effect of a secondary reinforcement stimulus on the auditory startle response.
Psycheolonical Reperts. 1964, 14 5:35-540.

BROWN, J. S., KALISH, H. I, \& FARBER. I. E. Conditioned fear as measured by magnitude of startle response to an auditory stimulus. Journal of Experimental Psychology, 1951, 41, $317-328$.

COHEN, L. H. The relationship between refractory phase and negative adaptation in reflex response. Journal of Comparative Psychology, 1929, 9, 1-16.

DAVIS, 11 Effects of interstimulus interval length and variability on startle-response habituation in the rat. Journal of Comparative \& Physiological Psychology, $1970,72,177-192$.

DAVIS, M., \& WAGNER, A. R. Startle responsiveness after habituation to different intensities of tone. Psychonomic Science, 1968, 12, 337-338.

DAVIS, M.. \& WAGNER, A. R. Habituation of startle response under an incremental sequence of stimulus intensities. Journal of Comparative \& Physiological Psy chology, 1969,67, 486-492.

GIBBINS, R. J., KALANT, H., LE BLANC, A. E., \& CLARK, J. W. The effects of chronic administration of ethanol on startle thresholds in rats. Psychopharmacologia (Berlin), 1971, 19, 95-104.
GROVES, P. M. \& THOMPSON, R. F Habituation: A dual process theory. Psychological Review, 1970, 77, 419-450. HOFFMAN, H S.. \& FLESHLER, M. Startle reaction: Modification by background acoustic stimulation. Science, $1963,141,928-930$

HORLINGTON, M. Startle response circadian rhythm in rats: Lack of correlation with motor activity. Physiology \& Behavior, 1970, 5, 49-53.

MOYER, K. E. Startle response: Habituation over trials and days, and sex and strain differences. Journal of Comparative \& Physiological Psychology $1963,56,863-865$

SOLLBERGER, A. Problems in the statistical analysis of short periodic time series. Journal of Interdisciplinary Cycle Research, 1970, 1, 49-88.

STERN, W. Effects of desynchronized sleep deprivation upon startle response habituation in rats. Psychonomic Science. $1971,23,31-32$

THOMPSON, R. F., \& SPENCER, W. A. Habituation: A model phenomenon for the study of neuronal substrates of behavior. Psychological Reviev, 1966. $73,16-43$.

WAGNER, A. R. Conditioned frustration as a learned drive. Joumal of Experimental Psychology, 1963, 66, 142-148.

\section{CURRENT LITERATURE ON EMOTIONAL BEHAVIOR IN ANIMALS}

B A L D E R R A M A, N . , \& MALDONADO, H. '(Centro' de Biofísica $y$ Bioquímica, Instituto Venezolano de Investigaciones Cientificas, Apartado 1827, Caracas, Venezuela). Habituation of the deimatic response in the mantid (Stagmatoptera biocellata). Journal of Comparative and Physiological Psychology, 1971, 75, 98-106.

BARRETT, R. J. (Psychology Research Laboratories, Veterans Administration Hospital, Nashville, Tenn. 37203), HUGHES, R. A., \& OAKLEY, S. R. ECS disruption of time-dependent processes in discriminated-avoidance conditioning in rats: Incubation or consolidation? Journal of Comparative and Physiological Psychology, 1971, 74, 319-321.

BINTZ, J. (University of California, Davis, Calif. 95616). Between- and within-subject effect of shock intensity on avoidance in goldfish (Carassius auratus). Journal of Comparative and Physiological Psychology, 1971, 75, 92-97.

BLACK, M., \& SUBOSKI, M. D. (Queen's University, Kingston, Ontario, Canada). Incubation and
ECS-produced gradients in one-trial and multitrial discriminatedavoidance conditioning in rats. Journal of Comparative and Physiological Psychology, 1971, 74, $325 \cdot 330$.

BOE, E. E. (Graduate School of Education, University of Pennsylvania, Philadelphia, Pa. 19104). Variable punishment. Journal of Comparative and Physiological Psychology, 1971, 75, 73-76.

CAIRNS, R. B. (Indiana University, Bloomington, Ind. 47401) \& NAKELSKI, J. S. On fighting in mice: Ontogenetic and experiential determinants. Journal of Comparative and Physiological Psychology, 1971, 74, 354-364.

DeVIETTI, T. L. (Central Washington State College, Ellensburg, Wash. 98926) \& LARSON, R. C. ECS effects: Evidence supporting state-dependent. learning in rats. Journal of Comparative and Physiological Psychology, 1971, 74, 407-415.

DUNCAN, N. C., GROSSEN, N. E., \& HUNT, E. B. (University of Washington, Seattle, Wash. 98105).
Apparent memory differences in inbred mice produced by differential reaction to stress. Journal of Comparative and Physiological Psychology, 1971, 74, 383-389.

DUNCAN, P. M. (Department of Physiology and Biophysics, University of Washington, Seattle, Wash. 98105). Effect of temporary septal dysfunction on conditioning and performance of fear responses in rats. Journal of Comparative and Physiological Psychology, 1971, 74, 340-348.

EICHELMAN, B. S., JR. (National Institute of Mental Health, Bethesda, Md. 20014). Effect of subcortical lesions on shock-induced aggression in the rat. Journal of Comparative and Physiological Psychology, 1971, 74, 331-339.

ENT I NGH, D. (Neurobiology Curriculum, Department of Biochemistry, School of Medicine, University of North Carolina, Chapel Hill, N.C. 27514). Perseverative responding and hyperphagia following entorhinal lesions in cats. Journal of Comparative and Physiological Psychology, 1971, 75, 50-58. 